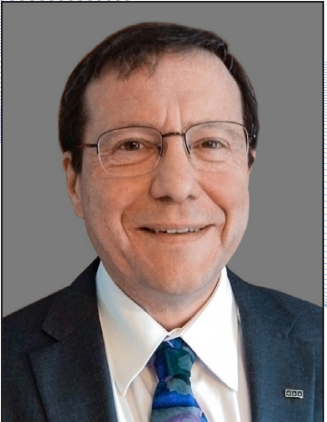

Matt Copel

2020 MRS President

\title{
Pioneering a new publishing model
}

The Materials Research Society (MRS) is moving to a publication alliance with Springer Nature beginning January 2021. What do you feel are the most valuable benefits of MRS' alliance with Springer Nature, and the impact on the MRS publications portfolio?

I am tremendously excited that my last communication as MRS President will be to discuss a positive development for our Society_-building a lasting relationship with the academic publishing company Springer Nature. Our intent is to initiate a broad-ranging alliance that will extend beyond the traditional roles of a scientific society and a publisher. We are interested in exploring deeper ties between our organizations to advance the careers of MRS Members and to further the MRS Mission at our meetings, via webinars and workshops, and, of course, through new publication collaborations. Not only are our Chair of Publications, Shefford Baker, and our Director of Communications, Eileen Kiley, committed to this idea, but the Springer Nature organization is as well. The hope is that we will pioneer a new model for how a publisher and nonprofit society can better serve the community. I should also add that Springer Nature has an unparalleled record of success in scientific publishing, which can only stand to benefit our own efforts.

How do you feel this alliance will help us to better serve the publications needs of our membership and the broader materials community?

We are entering into an alliance with a publisher with superb marketing acumen that extends to a global scope. If you are considering where to submit a manuscript, one of the primary considerations is readership. Having a premiere publishing house supporting your work is a strong draw. In addition, you will have the same familiar editors and staff that have made MRS Publications a warm, receptive place that welcomes the best in materials research. It is worth emphasizing that MRS will retain full editorial control over our products, so those of you who have already worked with our editors will feel right at home. And for those who are completely new to publishing, MRS and Springer Nature offer author workshops that will guide you through the manuscript preparation and submission process.

The current COVID-19 pandemic has affected so many aspects of our professional lives (as well as our personal lives). How has the pandemic affected scientific publishing?

We are still grappling with the effects of the pandemic on our profession. Not only is it harder to accomplish our research goals, but it is harder to communicate our hard-won results, especially in the absence of face-to-face meetings. So that means there is a lot more at stake when we publish. Readership of MRS journals has increased significantly in 2020, so we have seen that the demand for quality content remains strong. To better facilitate the communication of research, MRS journals allow for the submission and publication of figures and content, following standard peer review, that have appeared online as part of a virtual presentation. 
As you conclude your term as MRS President for 2020, what are some of the highlights and challenges of this past year?

Our Society had a full plate this year, even before the pandemic, with three major efforts. I've been discussing the publications transition from our members' perspective, but this also required a heavy lift by our Publications team. At the same time, our Meetings organization was asked to replace a recurring Spring Meeting in Phoenix with a rotation among Seattle, Honolulu, and San Francisco. Our Vice President Cherie Kagan led our third effort, a task force on governance reform. We refer to these three initiatives as a perfect storm. If we had only known how much bigger a storm was brewing! I'm happy to say that all three of these efforts are going forward, which is a testimonial to the dedication of the staff and volunteers.

There is no doubt that I've most enjoyed all the interactions with volunteers and staff. Experiencing all the enthusiasm, creativity, and wisdom has been a pleasure. A particular high point has been hearing the elation when an award winner first learns about his or her honor. I've also gotten a real charge out of acting as a spokesman for MRS. Whether through presidential letters, interviews, or other formats, it is immensely satisfying to speak for a cause in which you truly believe. Sometimes the message wasn't exactly good news, which is why I wanted to start my last presidential message on a positive note. I am optimistic that despite considerable headwinds, this year we prepared the Society for a strong future, where my successors will be able to speak to you about many, many great things.

Matt Copel

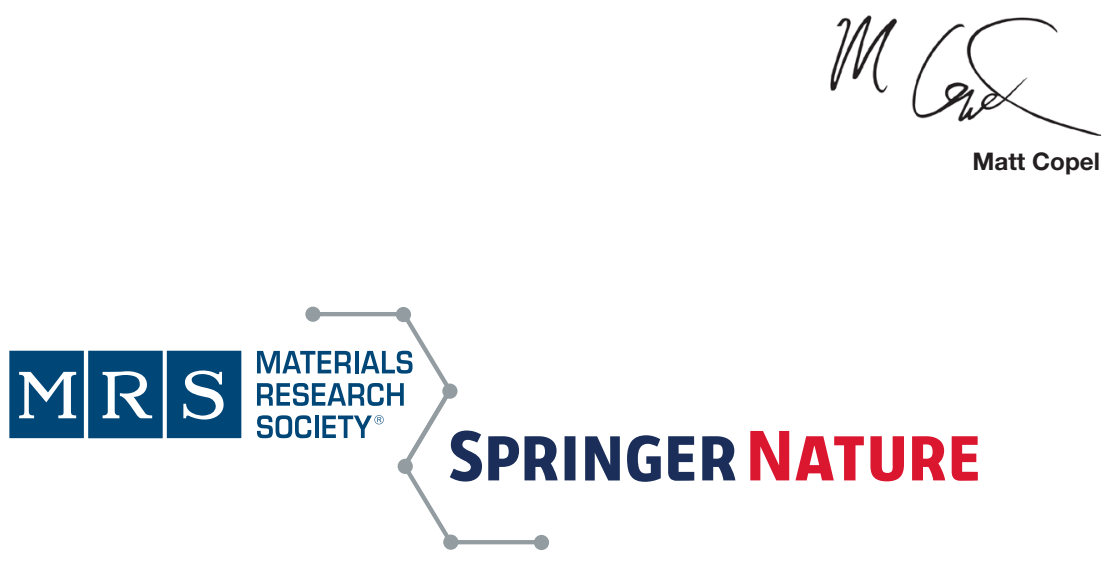

